\title{
Possibility to Improve Strength and Structural Stability of Bridge Deck Slabs by Using Ultra High Performance Fiber Reinforced Concrete
}

\author{
Nazar S., ${ }^{1}$, Ismaiel M.A., ${ }^{2}$ Ahmed M., ${ }^{3}$ \\ 1, 2, 3(Department of Civil Engineering, College of Engineering/ King Khalid University Abha, Saudi Arabia)
}

\begin{abstract}
Parts of the bridges in Sweden and other countries have shown to have a too low resistance with respect to deterioration. This leads to costly repair interventions that disturbs the traffic and results in high Life Cycle Costs (LCC) for the bridges. This investigation primarily focuses on the mechanical behavior, durability and rheological properties and application of UHPFRC to develop more robust bridge deck slabs. UHPFRC shows better performance at post-cracking due to the strain hardening behavior with distributed micro-cracks, enhancing the service life of bridge deck slabs. The main idea is to use Ultra-High Performance Fiber Reinforced Concrete (UHPFRC) to "harden" those zones of the structure that are exposed to severe environment and high mechanical loading. This conceptual idea combines efficiently protection and resistance properties of UHPFRC and significantly improves the structural performance of the rehabilitated concrete structure in terms of durability and life-cycle costs. The concept is validated by means of four applications demonstrating that the technology of UHPFRC is mature for cast in-situ and prefabrication using standard equipment for concrete manufacturing. Moreover an inventory of two bridges in Sweden has been used as case study to investigate the possibility of use of UHPFRC for rehabilitation.
\end{abstract}

Keywords: Bridge deck slabs, Interventions, Robust, Strain hardening, UHPFRC.

\section{INTRODUCTION}

Reinforced concrete is the most widely used construction material for bridges. The bridge decks are constantly subjected to concentrated traffic loads and are exposed to environment actions. Consequently, they deteriorate faster than other parts of the bridge. Also during winter, de-icing salts are used to keep the roads and bridges free from ice. De-icing salts, which are generally a mixture of sodium chloride and calcium chloride penetrate into the concrete and cause deterioration of the concrete structure and in particular, the steel reinforcement. These structures show excellent performance in terms of structural behavior and durability except for those zones that are exposed to severe environmental and mechanical loading [1].

Rehabilitation of deteriorated concrete structures is a heavy burden also from the socio-economic viewpoint since it also leads to significant user costs. As a consequence, novel concepts for the rehabilitation of concrete structures must be developed. Sustainable concrete structures of the future will be those requiring just minimum interventions of only preventative maintenance with no or only little service disruptions. Over the last 10 years, considerable efforts to improve the behavior of cementicious materials by incorporating fibers have led to the emergence of Ultra-High Performance Fiber Reinforced Concretes (UHPFRC). These novel building materials provide the structural engineer with an unique combination of (a) extremely low permeability which largely prevents the ingress of detrimental substances such as water and chlorides and (b) very high strength, i.e., compressive strength higher than $150 \mathrm{MPa}$, tensile strength higher than $10 \mathrm{MPa}$ and with considerable tensile strain hardening (up to more than $2 \%$ of strain) and softening behavior (with fracture energy of more than $15^{\prime} 000 \mathrm{~J} / \mathrm{m} 2$ ). In addition, UHPFRC have excellent rheological properties in the fresh state allowing for easy casting of the self-compacting fresh material with conventional concreting equipment [2].

Consequently, UHPFRC has an improved resistance against severe environmental and mechanical loading thus providing significantly improved structural resistance and durability to concrete structures. This paper presents an original concept for the rehabilitation of concrete structures. The concept is described and validated by means of four applications. Finally, two case studies were performed. In the first case study, the use of UHPFRC for rehabilitation of existing bridges was theoretically applied on a bridge deck slab.

An existing bridge with insufficient durability for the deck slab and deteriorated edge beams was chosen as a reference bridge. In second case study, a comparison was made between an industrially produced bridge alternative and a reference composite bridge, conventionally produced with a cast in-situ normal strength concrete bridge deck slab. The new alternative bridge solution considered of main steel girders and prefabricated normal strength bridge deck elements joined and covered with UHPFRC. 


\section{DETERIORATION OF BRIDGE DECK SLABS}

Bridge decks are constantly subjected to concentrated traffic loads and are exposed to environment actions. Consequently, they deteriorate faster than other parts of the bridge. Also during winter, de-icing salts are used to keep the roads free from ice and they are spread over the bridge decks. Chlorides ingress from the concrete cover mainly leads to pitting corrosion of the reinforcement. The total time to concrete cracking due to corrosion consist of two stages. In the first stage carbon dioxide and chlorides will take time to reach the steel; this can be considered as safe service life. The residual service life, in which corrosion takes place, continues until the limit state is reached and cracking and spalling of concrete way appear during this stage; see Fig. 1 [3]. Deck accessories exhibit various types of damages and these damages can be of different importance e.g. damages to the connection between edge beam and slab, expansion joints, water proving membranes, pavement and elements of drainage system are most dangerous [4].

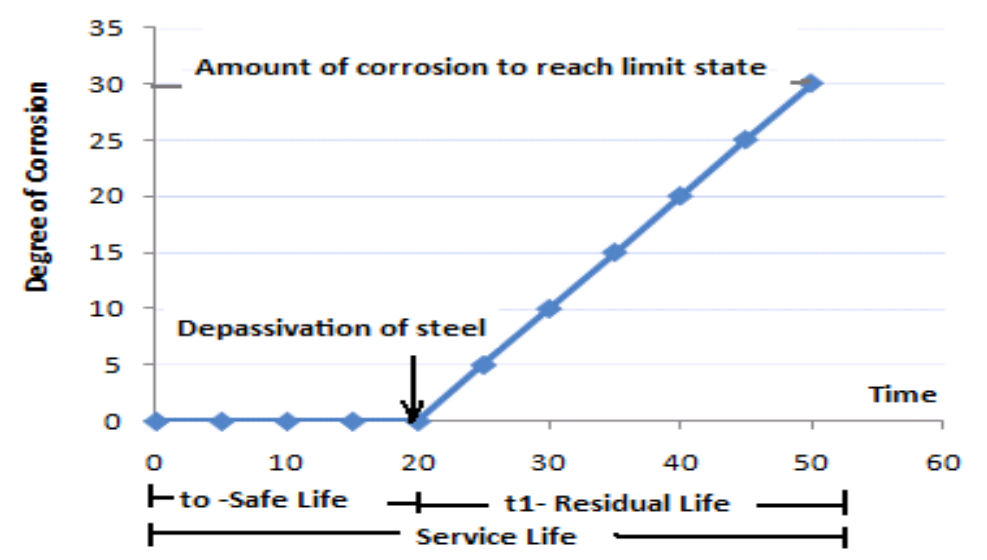

Figure 1: Service life model of reinforced concrete exposed to a corrosive environment.

\section{POSSIBLE SOLUTION WITH UHPFRC}

Research began very early for increasing both compressive and tensile strengths of concrete. The structure, composition and strength of concrete have been studied at micro and macro level. As a result, Ultra High Performance Fiber Reinforced Concrete (UHPFRC) has been evolved which is a more flexible, workable, durable and strong concrete material. It has high compressive and tensile strengths along with high ductility [5].

\subsection{Composition of UHPFRC}

UHPFRC consists of cement, sand, silica fume content, high super plasticizer, water and fibers. The water cement ratio is maintained at 0.15 to 0.20 [6]. The comparison of composition and properties of Normal concrete and UHPC can be seen in the Table 1.

Table 1:Comparison of composition and properties of NSC and UHPFRC [8]

\begin{tabular}{|c|c|c|c|}
\hline \multirow{8}{*}{ 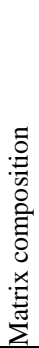 } & & NSC & UHPFRC \\
\hline & Component & $\mathrm{Kg} / \mathrm{m}^{3}$ & $\mathrm{Kg} / \mathrm{m}^{3}$ \\
\hline & Portland cement & $<400$ & $700-1000$ \\
\hline & Coarse aggregate & $\approx 1000$ & $0-200$ \\
\hline & Fine aggregate & $\approx 700$ & $1000-2000$ \\
\hline & Silica fume & - & $200-300$ \\
\hline & Super plasticizer & - & $10-40$ \\
\hline & water & $>200$ & $110-200$ \\
\hline & Water-cement ratio & $>0.35$ & $<0.24$ \\
\hline & Reinforcement/Fibres $\left(\mathrm{kg} / \mathrm{m}^{3}\right)$ & No Fibres & $>150$ \\
\hline \multirow{5}{*}{$\begin{array}{l}\stackrel{0}{0} \\
\frac{\vec{E}}{0} \\
\stackrel{0}{0} \\
0\end{array}$} & Density $\left(\mathrm{kg} / \mathrm{m}^{3}\right)$ & $2000-2800$ & $>2500$ \\
\hline & Compressive strength (MPa) & $<60$ & $>150$ \\
\hline & Tensile strength $(\mathrm{MPa})$ & $<3$ & $>8$ \\
\hline & Modulus of elasticity (GPa) & $\approx 30$ & $50-70$ \\
\hline & Fracture energy $\left(\mathrm{J} / \mathrm{m}^{2}\right)$ & $30-200$ & $>10000$ \\
\hline
\end{tabular}




\subsection{Properties of UHPFRC}

\subsubsection{Permeability}

To study the permeability of UHPFRC under high stresses, one of the researches has been conducted at the Swiss Federal Institute of Technology (EPFL). Uni-axial tensile and permeability tests were conducted on the UHPFRC called CEMTEC multiscale $^{\circledR}$. The specimens were cured for 28 days and Uni-axial tensile tests were carried out to get desire deformation of $0.13,0.25,0.5,0.75$ and $1 \%$. It was also observed that cracking did not influenceequivalent water permeability of core specimen significantly until deflection of $\epsilon_{t}=0.13 \mathrm{~mm}$ for 100 $\mathrm{mm}$ specimen and for NSC it was $0.05 \mathrm{~mm}$. Furthermore, the permeability of uncracked UHPFRC was found $1 \times$ $10^{-10} \mathrm{~cm} / \mathrm{s}$ and for NSC it was found $5 \times 10^{-9} \mathrm{~cm} / \mathrm{s}$. This difference between is due to multiple micro-cracking in UHPFRC instead of few micro-cracks develop in NSC. While micro-cracks are less permeable than discrete cracks in normal strength concrete [7].

\subsubsection{Mechanical response in Tension and Compression}

In 2004, Habel K., performed uniaxial tests to study the tensile behavior of UHPFRC. Strain hardening is one of the most distinguishing characteristics of the UHPFRC. The Tensile behavior of UHPFRC is shown in Fig. 2. Elastic deformation is obtained up to point A. At this stage, multiple micro cracks develop in the concrete. Strain hardening response is till point B and this effect is due to the pull out behavior of the fibres. The deformation in UHPFRC is still uniformly distributed and can be expressed by the strain $\varepsilon$. After point B, localization of cracks occurs and a softening behavior starts. The deformation behavior can then be expressed by stress-crack opening curve [6].

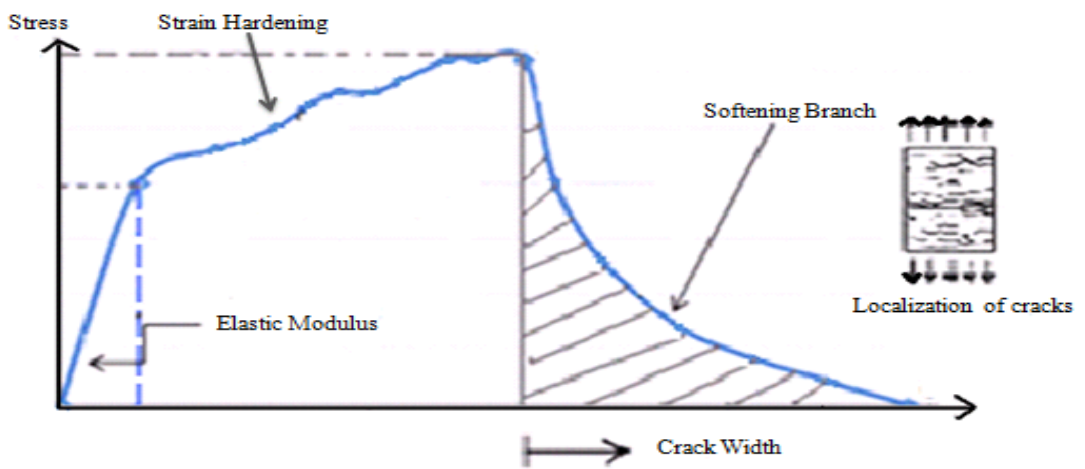

Figure 2: Typical stress-strain response of UHPFRC.

UHPFRC has a compressive strength of more than $150 \mathrm{MPa}$ and shows a ductile post-peak behavior due to stress-transfer mechanism of the micro cracks. The elasticity modulus, E is in range of 50-70 GPa. Ultra High Performance concrete (UHPC) shows brittle behavior under compression, but addition of fibres impairs the effect of the brittle behavior and also increases the compressive strength as shown in Fig. 3 [8]. The figure above shows the compressive behavior of the UHPFRC, Ultra high performance concrete without fibres and normal strength concrete. There is linear stress-strain relationship before peak load. Post-peak part is non linear and shows the softening behavior of the UHPFRC. While ultra high performance concrete shows brittle behavior after peak load.



Figure3: Stress-strain relationship of different UHPFRC's in Compression 


\subsection{Types of UHPFRC}

There are different types of UHPFRC materials available on the market, differing mainly regarding their mixture composition. Mainly there are three types of UHPFRC mixtures which are Compact ReinforcedComposites (CRC), Reactive Powder Concrete (RPC) and Multi-Scale Fiber Reinforced Concrete (MSFRC).Following the idea of these three types, different brands of UHPFRC are available on the market, developed by different companies. The modification has been done in these three types according to the composition of the mixture. Different types of UHPFRC materials and brands are listed and described in the Table 2.

Table 2: Mechanical properties of different types of UHPFRC.

\begin{tabular}{|l|c|c|c|c|c|}
\hline Mechanical properties & CRC & RPC & Ductal $^{\circledR}$ & CEMTEC $_{\text {multiscale }}{ }^{\circledR}$ & BSI $^{\circledR}$ \\
\hline Compressive strength(MPa) & $140-400$ & $200-800$ & $150-200$ & 180 & 190 \\
\hline $\begin{array}{l}\text { Bending tensile strength } \\
\text { (MPa) }\end{array}$ & $30-200$ & $30-50$ & $25-40$ & 25 & 9 \\
\hline Young's Modulus(GPa) & $40-80$ & $50-60$ & $50-55$ & 50 & 60 \\
\hline Density $\left(\mathrm{kg} / \mathrm{m}^{3)}\right.$ & $2600-3000$ & & 2500 & 2500 & 2700 \\
\hline
\end{tabular}

\subsection{Applications of UHPFRC}

\subsubsection{SAMARIS (Sustainable and Advanced Materials for Road Infrastructures) European Project}

In 2004, during the European project SAMARIS, UHPFRC was first applied for rehabilitation of existing concrete structures in Europe. A bridge over the river La Morge in Switzerland was rehabilitated and widened using UHPFRC of the $\mathrm{CEMTEC}_{\text {multiscale }}{ }^{\circledR}$ family. The bridge had no water proofing membrane and the edge beams were severely damaged by chloride ingress. The bridge was rehabilitated in three steps. In the first step the bridge was widened by a prefabricated UHPFRC edge beam and a reinforced beam. Then, the existing concrete overlay and edge beam were replaced by a UHPFRC overlay and edge beam respectively, as shown in Fig. 4. An economical analysis was done by comparing conventional methods of intervention. The construction cost of the UHPFRC intervention was found not significantly higher than the traditional methods for rehabilitation of bridge decks and the time for construction activities and closing of traffic lanes could be reduced [9].

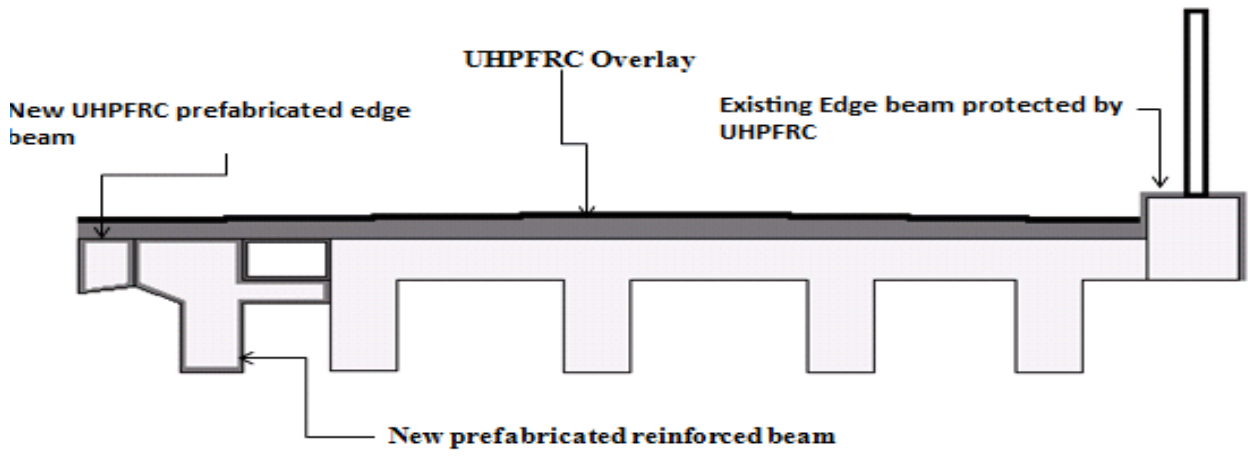

Figure 4: Cross Section of Bridge after rehabilitation with UHPFRC[9].

\subsubsection{Barrier (Parapet) Wall of Bridge}

A barrier wall on a bridge deck is subjected to severe environmental exposures such as splashing of deicing salts and also impact load from vehicles. However, when barrier walls are casted with UHPFRC, having low permeability and high ductility, they show excellent improvement of durability and mechanical properties [10].

\subsubsection{LOG ČEZOŠKI Bridge Slovenia}

In July 2009, UHPFRC was applied for the first time for rehabilitation of a bridge deck over Šoka River in Slovenia. The bridge was $65 \mathrm{~m}$ long having $5 \%$ longitudinal slope. It was a great challenge for the Engineers to modify the mixes of UHPFRC to tolerate to a slope of 5\%. Two recipes, one with thixotropic behavior and one with more fluid mix were used. The mechanical properties of the mixes were verified in the in-situ laboratory and through air permeability tests. The old concrete surface was made rough to get a good bonding to the UHPFRC. The upper surface of bridge, the footpath and the external side of the edge beams were casted with UHPFRC in two days as shown in Fig. 5. The Application of UHPFRC on a bridge deck in 
Slovenia presented the solution for the various deterioration problems without increasing rehabilitation costs. Moreover, rehabilitation of the bridge with UHPFRC was found more sustainable based on $\mathrm{CO}_{2}$ calculations [2].

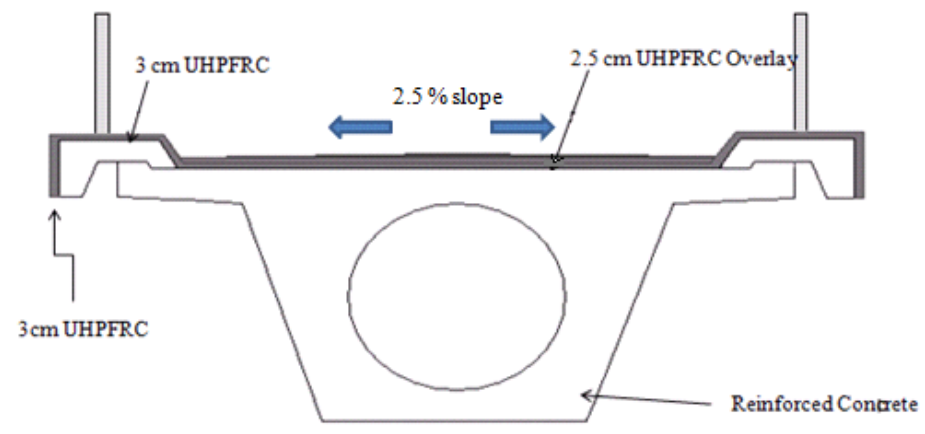

Figure 5: Cross section of bridge rehabilitated with UHPFRC [2].

\subsubsection{Use of Ductal ${ }^{\circledR}$ for Bridge Construction in Canada}

Another single span pedestrian bridge was constructed across an 8- lane highway, with the use of Ductal $^{\circledR}$ as construction material in Calgary, Alberta, Canada. The total length of the bridge is 53 meters. A deck 3.6 meters wide at the mid-span is resting on post tensioned girders. The girder is T-shaped with 33.6 meters length and 1.1 meter deep. Special type of passive reinforcement is used in which the bars are made up of glass fibre plastic. The abutments are also made up of UHPFRC. The T-shaped girder is a monolithic structure treated with heat of $90^{\circ} \mathrm{C}$ to ensure required strength and durability. The use of Ductal ${ }^{\circledR}$ drop-in girders gives greater structural strength with reduced weight, quick installation, high resistance against chloride ingress, durability and superior aesthetics [11].

\subsection{The Källösund Bridge}

\section{Case Studies}

A case study is done in this section to study the rehabilitation of the Källösund Bridge in Sweden. The formation of cracks has been found in the edge beams. Moreover, the corrosion of reinforcements in the edge beams has also been observed. This lead to the spalling of concrete from edge beams. Investigations and test have been carried out to check the performance of the edge beams. It was found that the edge beams are failed to perform according to the design load and needs to be replaced.

The expansion joints of the bridge have been rehabilitated twice, in 1982 and in 1993. The major problem observed was the $10 \mathrm{~mm}$ movement of the joints due to spalling out of concrete and cracks formation. Due to this large gap in the joints the chloride water passed in the deck slab and damaged the underside of the slab. In 1980's the splitting out of concrete cover was observed from the undersides of the edge beams. During the inspection in 1990 it was found that the entire northern part of the edge beams is damaged and also some parts in the southern side are damaged. In 2002, thorough observations showed that both the edge beams are damaged along its entire length. In 2003 and 2004, the damaged edge beams have been replaced by new one [12]-[13]. Only after 3 months cracks were observed in parts of the edge beam again. Therefore, an alternative solution is presented here focussing on the potentials of UHPFRC.

Two recipes of UHPFRC CM32_11 and CM32_13 were selected for the rehabilitation of this bridge as shown in Table 3, following the guidelines of Denariéet al.2009.

Table 3: Composition of CEMTEC multiscale $^{\circledR}$ recipes [2].

\begin{tabular}{|l|c|c|}
\hline Components & CM32_11 & CM32_13 \\
\hline Cement & $763 \mathrm{~kg} / \mathrm{m}^{3}$ & $763 \mathrm{~kg} / \mathrm{m}^{3}$ \\
\hline Limestone (filler) & $763 \mathrm{~kg} / \mathrm{m}^{3}$ & $763 \mathrm{~kg} / \mathrm{m}^{3}$ \\
\hline Micro Fibres & $\mathrm{L}=1 \mathrm{~mm}$ & $\mathrm{~L}=1 \mathrm{~mm}$ \\
\hline Macro fibers & $\mathrm{L}_{\mathrm{f}}=10 \mathrm{~mm}$ & $\mathrm{~L}_{\mathrm{f}}=10 \mathrm{~mm}$ \\
\hline Slope tolerance & Limited & High \\
\hline
\end{tabular}

The surface of the existing concrete is made rough with hydro-jetting before the application of the UHPFRC to ensure good bonding between the two layers. The cross section of the bridge after rehabilitation is shown in Figure 6 and Figure 7. The edge beams and overlay of the deck slab will be monolithically cast on site with UHPFRC. There is no slope tolerance required for edge beam so it is to be casted by recipe CM32_11. However, slope is required for water drainage over the bridge deck. Therefore overlay is suggested to be casted with recipe CM32_13. 


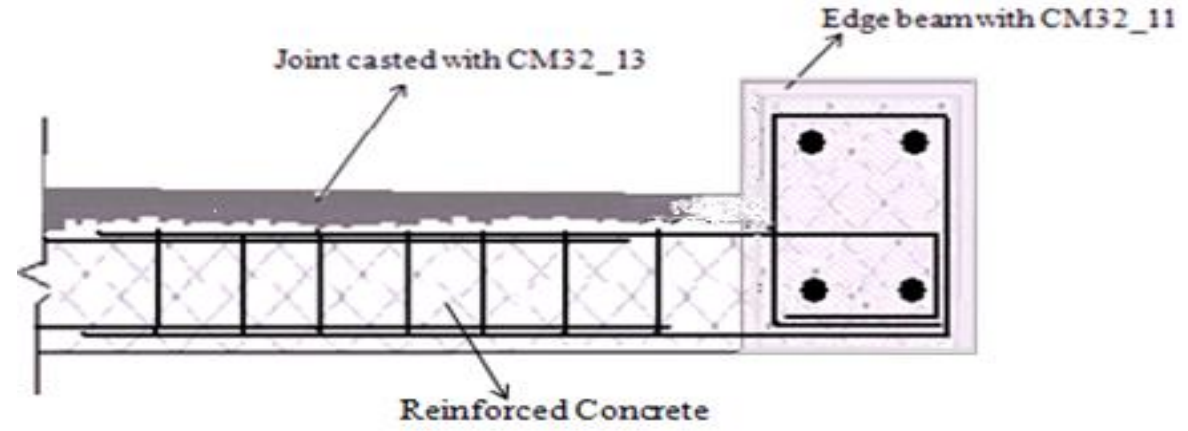

Figure 6: Proposed Cross Section of Edge beam and overlay casted with UHPFRC

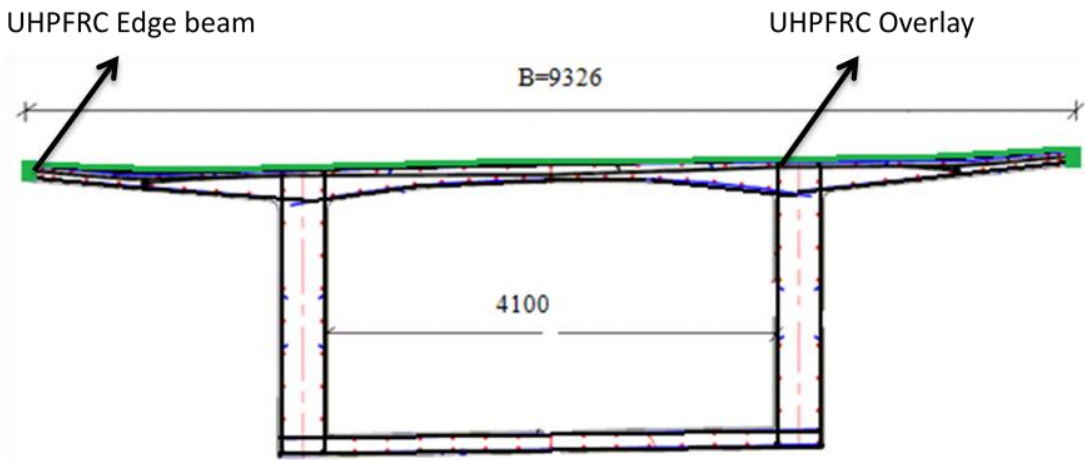

Figure 7: Cross section of Bridge after Rehabilitation with UHPFRC

A significant traffic passes over the bridge every day. Therefore, UHPFRC is to be casted in two steps on almost $10 \mathrm{~m}$ wide deck. In first step overlay is casted over one lane will be continuously moist cured. When the overlay will get enough strength, this lane is open to traffic. Similarly in second step other lane is to be casted with UHPFRC overlay. The overlay is casted continuously to expansion joints in such a way to avoid transverse dry joints. However, longitudinal joints between two layers will be specially designed to transfer the tensile forces between two layers. Typical longitudinal joint between UHPFRC layers was first applied during ARCHES project for the rehabilitation of Log Čezsoški bridge Slovenia as shown in Figure 8.

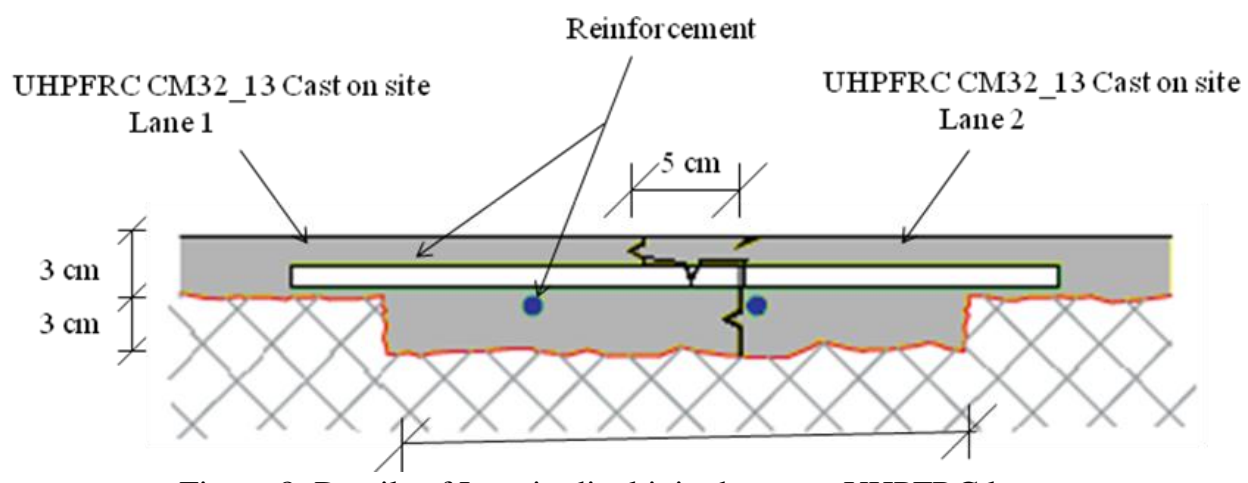

Figure 8: Details of Longitudinal joint between UHPFRC layers.

\subsection{Bridge Over Tolångaån}

Here application of UHPFRC for the construction of a new bridge is presented. Precast bridge deck slab has been proposed for this bridge. The bridge deck slab and edge beams are constructed with precast normal strength concrete. Precast elements of slab are connected together by UHPFRC joints. An overlay of UHPFRC is laid over the whole bridge including edge beam see Figure 9. The properties of NSC and reinforcement for the pre-cast slab will be selected according to the design specifications of the bridge. In case of cast in situ overlay, early age shrinkage of UHPFRC layer will be restrained which will develop tensile stresses in the new overlay. To overcome these stresses and obtain the delayed micro cracking even ultimate strength of matrix is reached, the UHPFRC must exhibit strain hardening. (For more details on restrain stresses see [14]. For this, UHPFRC needs less dispersion of mechanical properties due to fibrous mix. Many UHPFRC 
recipes are under development in the world. Very few recipes can satisfy at same time low permeability, strain hardening, high tensile and compression stress and self compactingbehavior. The recipes developed using lime filler as replacement of un-hydrated cement were found more suitable recipes which improved workability without compromising the strength of the matrix. In addition the slope tolerance of specific recipes was enhanced for cast in-situ application with slopes 3 to 5\%. These recipes are CM32_11 and CM32_13. The composition of these recipes is given in Table 7.2. Moreover, the recipes can be made very easily worldwide [2]. The bituminous concrete layer will be used over the UHPFRC layer to provide slope of $2.5 \%$ to both sides from centre for the drainage of water.

\subsubsection{Joint Details}

In 2008, Peter Harryson presented idea of casting of joints between prefabricated elements with UHPFRC. The aim of his work was to design a joint which is easy to install and perform better. Therefore, new joint $100 \mathrm{~mm}$ wide, with simple reinforcement detail was casted with CRC having water/binder ratio of about 0.16. Furthermore, these joints were tested for fatigue, shear and bending capacity in Chalmers University of Technology. The results showed that the joints become much stronger than the connecting parts if proper detailing of lap length is provided which was almost equal to $80 \mathrm{~mm}$. Moreover, the transverse reinforcement enhances the ductile behavior of the joint. For more details on tests on connection between prefabricated slabs casted with UHPFRC [15].

The basic conceptual idea is to use UHPFRC only in those zones of the structure where the outstanding concrete properties in terms of durability and strength are fully exploited. In this case, prefabricated joints are casted with CM32_11 as there is no slope requirement. The mechanical and durability properties of CM32_11 are almost similar to CRC except the composition of recipes. Despite this CM32_11 has significant tensile capacity to resist the retraining forces. Also it can be easily prepare in all over the world. The splice length of the reinforcement is equal to the width of the joint i.e. $100 \mathrm{~mm}$ as shown in Figure 10 (a) \& (b).

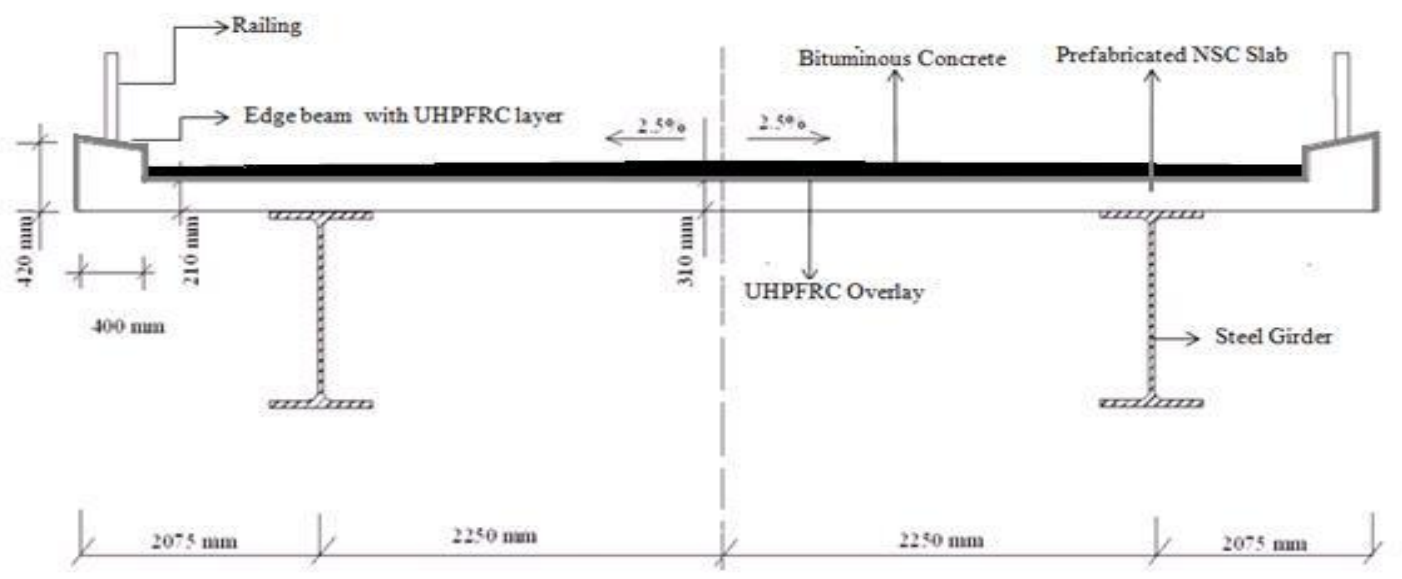

Figure 9: Proposed cross section of the composite bridge deck with NSC prefabricated Slab and UHPFRC Overlay

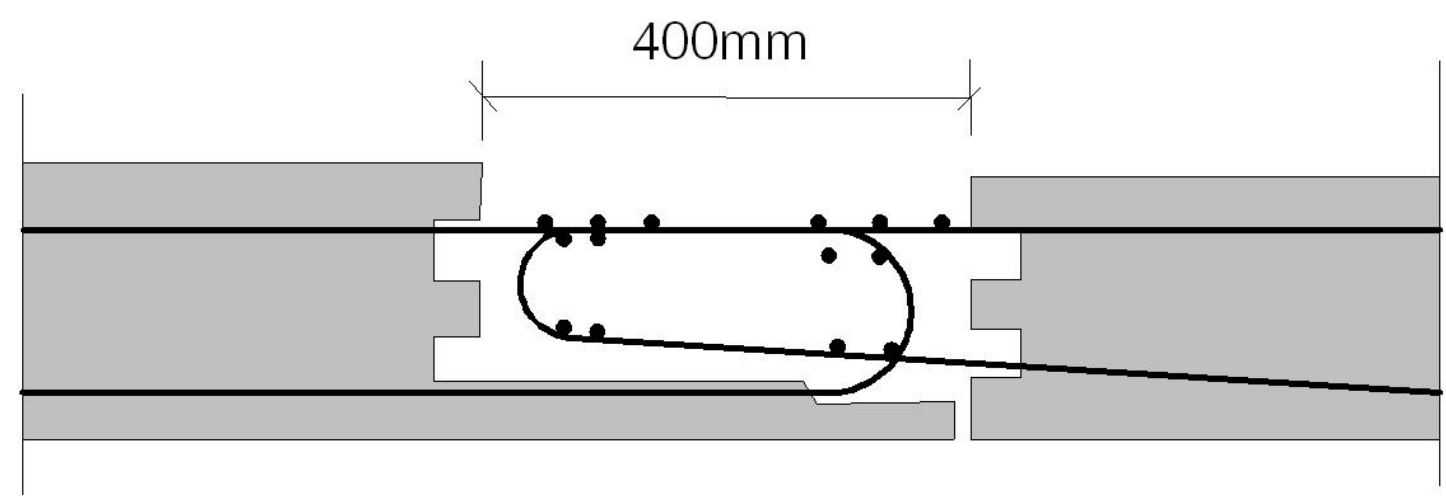

Figure 10(a). 


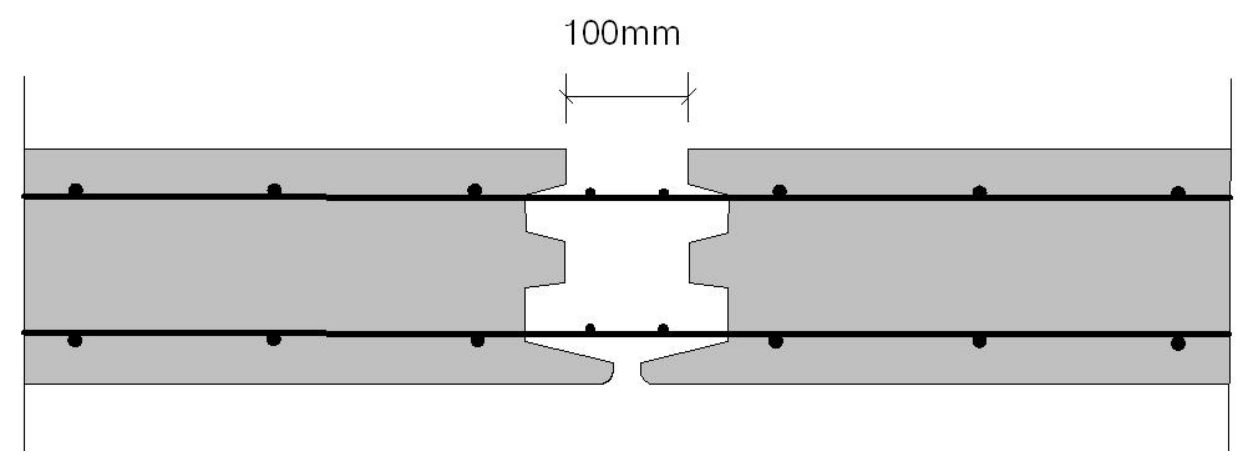

Figure 10 (b).

Figure 10: Joint between Prefabricated Slab casted with (a) Normal strength concrete (b) UHPFRC

\subsubsection{Application of UHPFRC Overlay}

After casting the connections between prefabricated deck slabs, a continuous $2.5 \mathrm{~cm}$ UHPFRC overlay of recipe CM32_13 with no dry joint is applied over upper face of bridge deck and edge beam. Despite this, sides of the edge beam are casted with recipe CM32_11 as no slope tolerance required. Formwork is used for casting of these layers of edge beam. However, formwork has to remain open from lower side to guarantee the continuity of the overlay over edge beam and upper face of deck without any dry joint as shown in figure 11 . The stiffness of the composite slab is significantly improved by the application of $2.5 \mathrm{~cm}$ thick UHPFRC layer.

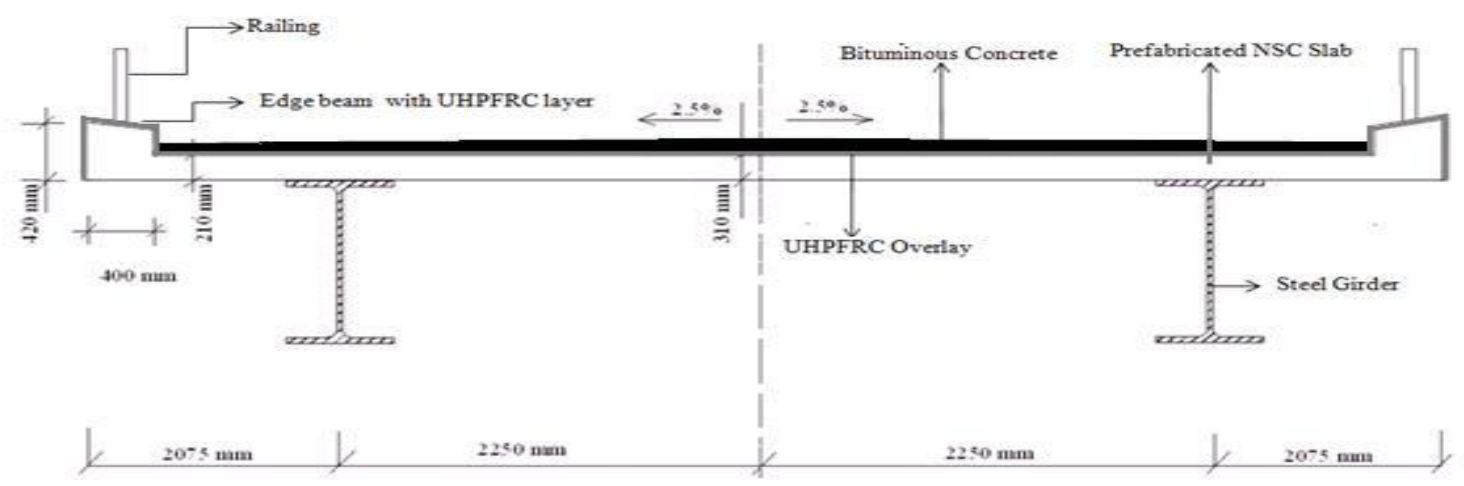

Figure 11: Proposed cross section of the composite bridge deck with NSC prefabricated Slab and UHPFRC Overlay

\section{Conclusions}

Bridge decks are constantly subjected to traffic loads and are exposed to environmental actions. Consequently they deteriorate faster than the other parts of the bridge. The use of de-icing salts leads to chloride penetration and corrosion of steel reinforcement.

Possible solution can be to have an impermeable and uncracked concrete cover. One way to obtained this is by using Ultra High Performance Fiber Reinforced Concrete (UHPFRC).

The UHPFRC has been found to be more resistant to chloride attack, freeze-thaw attack, alkali aggregate attack and abrasion in durability studies conducted by various researchers. Strain hardening is an essential property of UHPFRC since it keeps it less permeable even after crack initiation. Therefore, an overlay of UHPFRC shows better resistance against aggressive environmental effects and increases the service life of bridge deck slabs.

Successful rehabilitation of bridge deck slabs is a major issue. When a new layer of UHPFRC is applied over the existing concrete structure, a new composite structure is formed. Eigen stresses are produced in the new layer due to restrained shrinkage. Due to both deformability and strain hardening behaviour, the intensity of induced stresses is reduced.

UHPFRC has been applied to several bridges, both for rehabilitation and construction of new bridges. A sustainability study during the ARCHES project based on $\mathrm{CO}_{2}$ calculation showed that application of UHPFRC with $50 \%$ limestone filler was the most sustainable rehabilitation system compared to other standard system for rehabilitation.

The effect of using UHPFRC was studied in two case studies, in which the rehabilitation of an old bridge and the construction of a new bridge were compared to UHPFRC alternatives. The concept of application of UHPFRC was to use it where the structure is more exposed to severe environment actions and high traffic loads. 
This conceptual idea significantly improves the durability and decreases life cycle costs of both rehabilitated and new concrete structure.

Application of UHPFRC also reduces the layer thickness in case of rehabilitation and increases the capacity of structure without increasing deadweight.

UHPFRC also reduces the duration of rehabilitation works; traffic lanes can be open after few days. UHPFRC Bridge is taken into account and the user cost and special benefits of UHPFRC is added in the calculation, the bridge deck cost can be reduced by approximately $10 \%$.

The application of UHPFRC in the composite bridge construction with prefabricated elements enhance the service life of the bridge deck slab by providing stronger joints between the prefabricated bridge deck elements and by applying a non-permeable UHPFRC overlay on the bridge deck slab.

A major advantage of prefabricated construction is shorter construction time. Prefabricated concrete members have potential to be more durable than the cast in-situ concrete if they are made in controlled construction environment in factory. However initially more investment is required for plant machinery in case of prefabrication of concrete but this investment proves to be economical over cost time saved.

\section{References}

[1] Frangopol, D.M., Bruhwiler, E., Faber, M. H., Adey, B., (2003): Life-cycle performance of deteriorating structures: assessment, design and management. American Society of Civil Engineers. p. 133-140.AASHTO (2010): AASHTO LRFD Bridge Design Specifications, Customary U.S. Units, 5th Edition, with 2010 Interim Revisions, Washington, DC.UBC-1997: Structural Design Requirements, Vol. 2: International Conference of Building Officials, California, USA, 1997.

[2] Denarié, E., (2009): Recommendations for the tailoring of UHPFRC recipes for rehabilitation, ARCHES Project, Report No. ARCHES-05-DE06. Ver. Final, pp.78.

[3] Domone, P., Illston, J. (2010) Construction Materials- Their nature and behavior. Fourth Edition, Spon Press New York, 567. pp.566.

[4] Radomski, W., (2002): Bridge Rehabilitation. Warsaw University of Technology, Poland. 476 pp.

[5] Rossi, P., Chanvillard, G., (2000): Fiber Reinforced Concretes (FRC) BE-FIB, RILEM publications S.A.R.L. ENS-61 Av Pdt Wilson, F-94235 CachanCedex, France. P 87 - 100.

[6] Habel, K. (2004): Structural behavior of elements combining ultra-high performance fiber reinforced concretes (UHPFRC) and reinforced concrete. Ph.D. Thesis.Laboratory for Maintenance and Safety of Structures (MCS), School of Architecture, Civil and Environmental Engineering, Swiss Federal Institute ofTechnology in Lausanne (EPFL), THÈSE NO 3036, Lausanne, Switzerland. $195 p$.

[7] Charron, J.P., Denarie, E., Bruhwiler, E. (2006): Permeability of ultra high performance fibre reinforced concrete (UHPFRC) under high stresses, Material and Structures, Vol. 1 / 1968 - Vol. 44 / 2011, pp.269-277.

[8] Spasojević, A., (2008): Structural Implications of Ultra-High Performance Fiber-Reinforced Concrete in Bridge Design. Ph.D. Thesis NO 4051. Structural Concrete Laboratory, School of Architecture, Civil and Environmental Engineering,Swiss Federal Institute of Technology in Lausanne (EPFL), Lausanne, Switzerland, 199 pp.

[9] Denarié, E., (2005): Full Scale Application of UHPFRC for the Rehabilitation of Bridges-from lab to the field, SAMARIS report, No. Sam_GE_DE22v03_01.\{December\} 2005, Ver. Final, pp. 63.

[10] Oesterlee, C., Denarié, E., Brühwiler, E., (2006): UHPFRC protection layer on the crash barrier walls of a bridge, Laboratory of Maintenance and Safety of Structures (MCS), EcolePolytechniqueFédéralede Lausanne (EPFL), Lausanne, Switzerland.

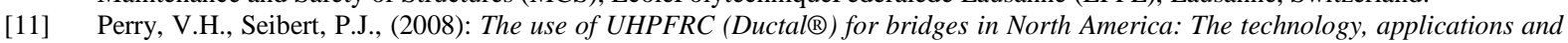
challenges facing commercialization. Structural Materials and Engineering Series, No.10, March 05-07, 2008, pp. 815-822.

[12] Samuelsson K., (2005): Sprickrisk vid byte avkantbalkar- inverkanavkylning, Master's Thesis. Department of Structural Engineering, Chalmers University of Technology, Publication no. 2005:29, Göteborg, Sweden.

[13] Faridoon F. A. \&Nazar S.,(2011): Development of more Robust Bridge Deck Slabs, Potential of Ultra High Performance Fiber Reinforced Concrete, Master Thesis No. 2011:72, Department of Civil and Environmental Engineering Structural Engineering, Concrete Structures, Chalmers University of Technology Sweden.

[14] Habel, K., Charron, j P., Braike, S., Hooton, R D., Gauvreau, P., Massicote, B., (2008): UHPFRC mix in Central Canada, Canadian Journal of Civil Engineering, Vol 35, No. 2, \{Feb 2008.

[15] Peter Harryson (2008): Structural developments for more efficient bridge construction, Ph.D. Thesis No.2810, Department of Civil and Environmental Engineering Structural Engineering, Concrete Structures, Chalmers University of Technology Sweden. 